\title{
Spatial distribution of job opportunities in China: Evidence from the opening of the high-speed rail
}

\author{
Wenming Shi \\ Maritime and Logistics Management, Australian Maritime College, \\ University of Tasmania, Launceston, TAS 7250, Australia \\ Wenming.Shi@utas.edu.au
}

Kun-Chin Lin

Department of Politics and International Studies, University of Cambridge, UK

kc135@.cam.ac.uk

Heather McLaughlin

Faculty of Business and Law, Coventry University, Coventry CV1 5DL, UK

ac6039@coventry.ac.uk

\section{Guanqiu Qi}

Department of International Logistics, Chung-Ang University, Seoul, South Korea

xiao20107@cau.ac.kr

\begin{abstract}
Mengjie Jin*
Jiangsu Key Laboratory of Modern Logistics, School of Marketing and Logistics Management, Nanjing University of Finance and Economics

No.3 Wenyuan Road, Xianlin College Town, Nanjing, China

mengjiejin@nufe.edu.cn
\end{abstract}

*To whom correspondence should be addressed. E-mail: mengjiejin@nufe.edu.cn

This study is supported in part by the Korea Foundation and Zhejiang University Education

Foundation Global Partnership Fund, and National Natural Science Foundation of China [Grant 71901116]. 
Spatial distribution of job opportunities in China: Evidence from the opening of the highspeed rail

\section{Highlights}

1. The provision of sufficient job opportunities is a primary concern for the central governments.

2. The opening of the HSR increases job opportunities at the national level.

3. Spatial dependence of job opportunities is found. 


\title{
Spatial distribution of job opportunities in China: Evidence from the opening of the high-speed rail
}

\begin{abstract}
The provision of sufficient job opportunities has traditionally been a primary objective for both local and central governments. In response to this concern, we investigate spatial dependence of job opportunities among 30 Chinese provincial capital cities (PCCs) from 2002 to 2016, giving special attention to the spatial spillovers of the opening of the high-speed rail (HSR). Using appropriate spatial panel data models, our findings suggest the presence of significant spatial autocorrelation of job opportunities among PCCs. Whilst the HSR has been found to increase job opportunities at the national level, which, however, is not confirmed at the regional level. The spatial spillover effects of the HSR are significant and positive only in the eastern/northeastern region. These findings can help the central government to more fully understand spatial dependence of job opportunities, better plan future HSR networks, and efficiently allocate transportation resources, encouraging cross-regional collaboration to promote regional employment.
\end{abstract}

Keywords: Job opportunities; High-speed rail; Spatial spillovers; Spatial panel data models 


\section{Introduction}

It is widely acknowledged that the provision of sufficient job opportunities is a traditional macroeconomic objective for the central government due to its vital role in promoting economic growth and economic equity. As a fundamental factor of production, the amount of labor employed to produce goods and services can, to a certain extent, determine the total output of an economy (Mankiw, 2010, p.47-49). Meanwhile, an economy with abundant labor resources, especially skilled and productive labor, which acquired skills through human capital and learning investment, can create its own competitive advantages by attracting more investors and capital, which in turn creates more jobs and generates economic prosperity and growth (Hatch and Dyer, 2004). The number of job opportunities provided in the economy can affect individuals in a direct and serious manner. Since most individuals rely on job earnings to maintain their standard of living, a shortage of job opportunities potentially causes an unemployment problem and lowers living standards in the present, as well as reducing the ability to access higher education, better housing, and more affordable healthcare services in the future, which in turn increases income inequality (Mankiw, 2015, p.579)

From the Cobb-Douglas (C-D) production point of view, an economy's outputs of goods and services depend on the quantities of its inputs (e.g., labor, capital) and its ability to combine those inputs to produce outputs, which is determined by the available production technology (Arrow et al., 1961; Mankiw, 2010, p.47). In other words, the number of job opportunities can be significantly affected by the production level indicated by economy size, capital stock, and the adopted technology. As a result, the local and central governments may use expansionary policies such as the construction of roads, railways, and bridges, to increase production capacity and create more job opportunities given the available production technology (Dalenberg et al., 1998). Furthermore, positive effects of transportation infrastructure improvements on employment have been empirically confirmed in previous studies (Levinson, 2012; Lee and Kim, 2015). This has encouraged the local and central governments to invest in developing transportation networks, especially the high-speed rail (HSR) networks in recent decades, in order to stimulate employment. In the case of China, particular economic, political and cultural considerations have led the central government to play a critical role in planning future HSR networks and allocating HSR investment among different regions (Chen et al., 2016). Such HSR investment requires a special consideration 
of spatial spillovers. Accordingly, a growing concern of the central government is how to separately assess impacts of the opening of the HSR on local and neighboring job opportunities when investing in the HSR networks. This particular topic has received little attention in the existing literature (Hensher et al., 2014; Dong, 2018; Heuermann and Schmieder, 2019), and will be addressed in the current study from the perspective of spatial econometrics.

The aforementioned spatial spillover effects of the opening of the HSR can be captured by the spatial panel data models (SPDMs). Therefore, this study uses the SPDMs to examine spatial dependence of job opportunities among 30 Chinese PCCs from 2002 to 2016. This study contributes to previous literature in three main areas. First, it considers a general SPDM without extra restrictions on the model specification, which helps to identify the most appropriate model to describe spatial dependence of job opportunities. Second, unlike previous studies which mainly use a spatial weight matrix based on either the inverse of geographic distance or the fact of being (or not being) neighbors to reflect the spatial influence among different PCCs, this study constructs an alternative spatial weight matrix based on the inverted absolute differences in the gross domestic product (GDP). This approach examines how economic distance affects the spatial distribution of job opportunities among PCCs. Third, to provide a clear and concise analysis, this study uses the C-D production function framework to highlight the most important factors affecting job opportunities, thereby avoiding an overly detailed investigation of influences on the demand and supply of labor force. Such simplification suggests strong cross-regional collaboration to promote employment, and also highlights the coordinative role of the central government in planning future HSR networks, allocating HSR investments, and creating job opportunities among PCCs.

The remainder of this study is organized as follows: Section 2 reviews previous studies and identifies the key research gaps. Section 3 introduces the methodology. Section 4 discusses the data collection and empirical results. Section 5 presents the discussion and policy implications. Section 6 draws conclusions.

\section{Literature review}

Many studies have been devoted to modeling the distribution of job opportunities under the demand-supply framework, aiming to identify the key factors that affect the demand and supply of 
job opportunities and examine labor mobility within and across regions. First and foremost, wage rate is generally believed to be the most important factor affecting labor demand-supply and labor mobility. For example, Lee and Wolpin (2006) assess how the wage difference between the service and the goods sectors influences intersectoral labor mobility using a two-sector labor market equilibrium model. Simonen et al. (2016) examine the impact of regional wage levels as well as other factors on inter- or intra-sector or region employment mobility in the high-tech sector in Finland. Due to its importance for job opportunities, wage rate has also received considerable attention in McLaughlin and Bils (2001), Beladi et al. (2008), Mitra and Ranjan (2010), and Dustmann et al. (2017). The second widely recognized factor is the regional unemployment rate. A higher unemployment rate usually indicates a shortage of job opportunities and a surplus of labor force, leading to higher labor movements away from the region (Decressin and Fatás, 1995; Eliasson et al., 2003; Finnie 2004; Simonen et al., 2016). Third, it is commonly accepted that transportation infrastructure improvements tend to increase regional accessibility and connectivity, which in turn reduces travel times and transportation costs (Arbués et al., 2015; Guirao et al., 2017). This not only facilitates cross-regional labor mobility and enlarges the available labor pool in a region, but also attracts more investments and businesses and creates more job opportunities (Chen and Haynes, 2017). Other factors extensively researched in previous studies include trade and technology advancement (Autor et al., 2015), policy reforms (Seeborg et al., 2000), housing prices (Haas and Osland, 2014), and commuting distance (Haller and Heuermann, 2016).

As a relatively new transportation mode, the HSR can greatly reduce the inter- and intra-regional travel time, and therefore many countries are enthusiastic about investing in expanding their HSR networks (Chen and Haynes, 2017). The top five countries ${ }^{1}$ with the most operational HSR are China $(25,000 \mathrm{~km})$, Spain $(3,100 \mathrm{~km})$, Germany $(3,038 \mathrm{~km})$, Japan $(2,765$ $\mathrm{km})$, and France $(2,647 \mathrm{~km})$. Nevertheless, the primary focus of previous studies has been how to use the HSR as an impetus to stimulate economic growth, while paying little attention to the distributional impact of the HSR on employment (Coto-Millán et al., 2007; Chen and Hall, 2012; Meng et al., 2018). Along with the ever-increasing concern about regional income disparities, the potential role of the opening of the HSR in distributing job opportunities has been re-emphasized.

\footnotetext{
${ }^{1}$ https://www.worldatlas.com/articles/countries-with-the-most-high-speed-rail.html
} 
For example, using a supply-oriented regional econometric model, Sasaki et al. (1997) point out that the Japanese Shinkansen network expansion, to some extent, increases jobs in developed regions (e.g., Osaka and Tokyo) but reduces job opportunities in less-developed regions (e.g., Nagoya). This can be partially explained by the fact that the Shinkansen network expansion, especially in remote regions, also improves the accessibility of developed regions. Kim (2000) examines the spatial restructuring effect of the HSR developments between Seoul and Pusan and finds that population tends to concentrate toward Seoul and its fringe, whereas employment shows a greater dispersion over time. Benefiting from the expanded HSR network, some remote areas can be integrated into large metropolitan areas, potentially influencing intra-regional distribution of job opportunities by the HSR commuting (Garmendía et al., 2008; Guirao et al., 2017).

As previously mentioned, a variety of factors contribute to the modeling of job opportunity distribution. Of late, the growing application of spatial analysis in the labor market has enabled researchers to detect and assess how the local labor market can affect and be affected by neighboring labor markets, providing useful insights into spatial dependence of job opportunities. For instance, by using a spatial statistical approach, Kondo (2015) states that municipal unemployment rates in Japan display significant positive spatial autocorrelation. Haller and Heuermann (2016) examine the job matching process in Germany using the Spatial Durbin Error model and find that unemployment and vacancies present strong spatial spillovers. Kawabata and Abe (2018) apply the spatial regression approach to explore how commute times affect intra-metropolitan spatial patterns of female labor participation and suggest that significant spatial clusters can be observed. With the help of the matching function, Higashi (2018) reveals significant spatial spillovers in job matching, implying that the local job matching process can be affected by unemployment and vacancies in both the local and neighboring regions. The above spatial interdependence among labor markets can also be observed in Burda and Profit (1996) for the Czech Republic, Burgess and Profit (2001) and Manning and Petrongolo (2017) for the United Kingdom (UK), Niebuhr (2003) for European countries, Ilmakunnas and Pesola (2003) and Hynninen (2005) for Finland, and Lottmann (2012) for Germany.

Consequently, the following gaps can be identified and addressed in this study. First, previous studies make efforts to identify factors affecting the distribution of job opportunities under the demand-supply framework, which explain job search behavior and labor mobility within and 
across regions. However, the demand-supply framework provides limited insights into job creation by investigating how the central government can better allocate transportation resources, design the future HSR networks, and make the HSR investment decisions. To fill this gap, this study revisits the job opportunity distribution from the C-D production function perspective, highlighting the most important factors affecting the number of job opportunities. This simplification framework not only avoids an overly detailed investigation of the labor market, but also provides a macro perspective on job opportunity distribution. Second, regarding the spatial spillovers of the opening of the HSR, existing studies focus mainly on its impacts on economic growth rather than employment. This study, therefore, seeks to bridge this gap by considering the distributional impact of the opening of the HSR on job opportunities. In this way, this study sheds light on how the HSR can be used to promote job opportunities.

\section{Methodology}

As previously stated, this study uses SPDM as the basis for investigating spatial dependence of job opportunities created by the HSR. This section demonstrates how the C-D production function framework is used to highlight the most important factors affecting job opportunities, thereby avoiding an overly detailed investigation of influences on the demand and supply of labor force. On the other hand, this section also demonstrates how the alternative spatial weight matrix based on the inverted absolute differences in the GDP is constructed.

\subsection{Moran's I}

As suggested by Moran (1950), Moran's $I$ can provide preliminary evidence for spatial dependence of job opportunities, which is expressed as

$$
I=\frac{\sum_{i=1}^{n} \sum_{j=1}^{n} w_{i j}\left(x_{i}-\bar{x}\right)\left(x_{\bar{j}}-\bar{x}\right)}{\sum_{i=1}^{n}\left(x_{i}-\bar{x}\right)^{2}}
$$

where $n$ is the number of regions; $x_{i}$ and $x_{j}$ are the values of region $i$ and $j$ of variable of interest (i.e., job opportunities), respectively; $\bar{x}$ is the mean of $x$; and $w_{i j}$ is the $i j$ th element of the row-standardized spatial weight matrix $W$. Moran's $I$ lies within the range $[-1,1]$ and a positive (negative) Moran's $I$ indicates that positive (negative) spatial autocorrelation exists across regions. 


\subsection{Model specification}

To provide further evidence regarding the spatial dependence of job opportunities, we start by introducing the C-D production function and applying a general SPDM without extra restrictions on the model specification. More specifically, given the available production technology, the following standard C-D production function with one output and two inputs will be considered in this study (Hu and Liu, 2009; Yu et al., 2013; Arbués et al., 2015; Li et al., 2018).

$$
Y=f(K, L)
$$

where $Y$ denotes the output of the economy, reflecting the economy size $(E S) ; K$ is the amount of capital stock ( $C S$ ); and $L$ stands for the amount of labor input that can be used to practically measure how many job opportunities $(J O)$ are provided within a given period. In addition, $f$ represents the available technology for turning capital and labor into output and it is commonly supposed to be an inverse function in practice. As a result, $J O$ can be calculated as

$$
J O=f^{-1}(C S, E S)
$$

The log-linearized specification with consideration of the opening of the HSR is expressed as

$$
\ln J O=\alpha_{0}+\alpha_{1} \ln E S+\alpha_{2} \ln C S+\alpha_{3} H S R+\varepsilon
$$

where HSR refers to the opening of the HSR, taking on the value of one if the HSR service is provided and zero otherwise, and $\varepsilon$ is the error term and it is assumed to follow a normal distribution with zero mean and constant variance (Arbués et al., 2015). Notably, as an additional explanatory variable, the opening of the HSR is introduced into Equation 4 rather than the C-D production function, indicating the appropriateness of using the semi-log form of regression. The coefficient of HSR measures the relative change in $J O$ for a given absolute change in the value of $H S R$.

With respect to the presence of spatial dependence of job opportunities, the following general SPDM is considered (Yu et al., 2013).

$$
\begin{aligned}
\ln J O_{i, t}= & \tau \ln J O_{i, t-1}+\rho \sum_{j=1}^{n} w_{i j} \ln J O_{j, t}+\alpha_{1} \ln E S_{i, t}+\alpha_{2} \ln C S_{i, t}+\alpha_{3} H S R_{i, t} \\
& +\beta_{1} \sum_{j=1}^{n} w_{i j} \ln E S_{j, t}+\beta_{2} \sum_{j=1}^{n} w_{i j} \ln C S_{j, t}+\beta_{3} \sum_{j=1}^{n} w_{i j} H S R_{j, t}+u_{i}+\gamma_{t}+\varepsilon_{i, t}
\end{aligned}
$$




$$
\varepsilon_{i, t}=\lambda \sum_{j=1}^{n} w_{i j} \varepsilon_{j, t}+v_{i, t}
$$

where $n$ denotes the number of provincial capital cities in this study; $t$ is the index of year; $i$ and $j$ represent local and neighboring cities $(i \neq j)$, respectively; $u_{i}$ is the individual effect and $\gamma_{t}$ is the time effect; $w_{i j}$ and other variables are defined as before; and $\varepsilon_{i, t}$ reflects the spatially autocorrelated error terms. Additionally, $\rho$ and $\lambda$ are called the spatial autocorrelation coefficients and $\tau$ is the autoregressive parameter. It should be mentioned that one-period lagged GDP is used as a proxy measure of economy size to reduce possible endogeneity problem (Bellemare et al., 2017).

Furthermore, due to different geographic, cultural, and economic conditions in different regions, job opportunities usually spatially interact in different forms, which include the endogenous interaction effects among the dependent variables $\left(\sum_{j=1}^{n} w_{i j} \ln J O_{j, t}\right)$, the exogenous interaction effects among the independent variables $\left(\sum_{j=1}^{n} w_{i j} \ln E S_{j, t}, \sum_{j=1}^{n} w_{i j} \ln C S_{j, t}\right.$, $\left.\sum_{j=1}^{n} w_{i j} H S R_{j, t}\right)$, and the interaction effects among the error terms $\left(\sum_{j=1}^{n} w_{i j} \varepsilon_{j, t}\right)$. To identify the potential form of spatial interaction of job opportunities among different regions, four simplified SPDMs can be obtained by imposing constraints on the general model. They are the spatial Durbin model (SDM) if $\lambda=0$, the spatial autoregression model (SAR) if $\lambda=0$ and $\beta_{i}=0$ ( $i=1,2,3)$, the spatial autocorrelation model (SAC) if $\tau=0$ and $\beta_{i}=0 \quad(i=1,2,3)$, and the spatial error model (SEM) if $\tau=\rho=0$ and $\beta_{i}=0 \quad(i=1,2,3)$. Using the maximum likelihood estimation (MLE) method, the SPDMs will be estimated and tested in Stata15. The MLE technique is also helpful to reduce endogeneity problem.

In addition, it should be noted that the estimated coefficient of an independent variable does not directly reflect its marginal effect on the dependent variable (Golgher and Voss, 2016). To deeply understand spatial spillovers, LeSage and Pace (2009) suggest that the direct, indirect, and total effects of a change in an independent variable should be calculated. According to Golgher 
and Voss (2016), the direct effect of a change in an independent variable for a region on its own dependent variable includes not only the estimated coefficient but also the spillover feedback effects which pass through other regions and back to that region. The indirect effect measures the impact of a change in an independent variable in all other regions on the local region's dependent variable, which is commonly understood as spillover effects (Arbués et al., 2015). Then, the total effect, including both the direct and indirect effects, measures the impact of a change in an independent variable in all regions on the local region's dependent variable.

\subsection{Spatial weight matrix}

The binary contiguity (BC) weights are used to construct the spatial weight matrix, which assumes that only contiguous provinces (represented by the PCCs) can influence each other (Anselin and Griffith, 1988). Then, two PCCs $(i$ and $j$ ) can be identified as neighbors if the two provinces share boundaries and the corresponding element of the spatial weight matrix $\left(w_{i j}\right)$ takes on the value of one and zero otherwise (Yu et al., 2013; Rhee et al., 2016). Practically, the spatial weight matrix is usually row normalized, satisfying the condition of $\sum_{j=1}^{n} w_{i j}=1, i=1, \cdots, n$. In doing so, $w_{i j}$ can be interpreted as the fraction of all spatial influences on city $i$ attributable to city $j$.

This study also uses an alternative spatial weight matrix based on the inverted absolute differences in the GDP to examine how economic distance affects the distribution of job opportunities among PCCs (Próchniak and Witkowski, 2014). Such a matrix stems mainly from the row-normalized form of the power distance weights ${ }^{2}$ with the following specifications of distance and weight functions (Deng, 2014).

$$
\begin{gathered}
d_{i j}=\left|\overline{G D P_{i}}-\overline{G D P_{j}}\right| \\
w_{i j}=\left(d_{i j}^{-1}\right) / \sum_{k \neq j} d_{i k}{ }^{-1}
\end{gathered}
$$

where $\overline{G D P_{i}}$ and $\overline{G D P_{j}}$ are the average outputs of cities $i$ and $j$ over the sample period, respectively. $d_{i j}$ and $d_{i j}{ }^{-1}$ indicate the economic distance and its inverse. $w_{i j}$ is the corresponding element of the spatial weight matrix based on the economic distance.

\footnotetext{
2 https://www.seas.upenn.edu/ ese502/lab-content/extra_materials/SPATIAL\%20WEIGHT\%20MATRICES.pdf 


\section{Empirical analysis}

\subsection{Data collection}

To examine spatial dependence of job opportunities, this study estimates the SPDM using a balanced panel dataset of 30 Chinese PCCs $^{3}$ from 2002 to 2016, which yields 450 observations. The related data are collected from the China City Statistical Yearbooks from 2003 to 2017 and summarized in Table 1. First, job opportunities are measured by the year-end data of total employment in each PCC over the sample period. Second, as previously discussed, the economy size can be represented by the output of the economy. For this reason, nominal GDP is collected and converted to constant prices of 1978 using the GDP deflator to reduce the impact of inflation. Third, capital stock can be calculated using the following perpetual inventory method with an initial investment stock of each PCC in 2002 and a depreciation rate of 10.96\% (Goldsmith, 1951; Shan, 2008; Yu et al., 2013).

$$
K_{i, t}=(1-\delta) K_{i, t-1}+I_{i, t}
$$

where $\delta$ indicates the depreciation rate and $I_{i, t}$ indicates new investments in year $t$. The data for the calculated capital stock is converted to the constant prices of 1978 using the price index for investment in fixed assets. Finally, data relating to the opening of the HSR are collected from the HSR official website and other relevant sources ${ }^{4}$.

\section{Insert Table 1 about here}

As a preliminary detection approach, Moran's $I$ can provide some initial insights into the detection of spatial autocorrelation. Table 2 reports the results of Moran's $I$ with the economic distance (ED) weight matrix ${ }^{5}$. As shown in Table 2, job opportunities display significant spatial dependence, implying that the number of job opportunities in a PCC can be affected by neighboring PCCs' job opportunities.

\section{Insert Table 2 about here}

\subsection{Spatial spillovers at the national level}

After performing different forms of the SPDM, the SAR is identified as the most appropriate

\footnotetext{
3 Tibet is excluded from this study due to the unavailability of related data.

${ }^{4}$ http://www.gaotie.cn/; http://www.mot.gov.cn/; https://www.12306.cn/index/

${ }^{5}$ Spatial autocorrelation has been widely detected when using the BC weight matrix (Yu et al., 2013; Arbués et al., 2015; Rhee et al., 2016). Then, the corresponding Moran's $I$ is not repeated here.
} 
model to capture spatial dependence of job opportunities at the national level, which is demonstrated in Table 3. According to the Hausman test, it is significant at the $1 \%$ level in the case of the $\mathrm{BC}$ weight matrix, and it is also significant at the $5 \%$ level in the case of the ED weight matrix, suggesting the spatial fixed effect model regardless of the spatial weight matrix (Arbués et al., 2015). Second, as shown in Table 3, the spatial autocorrelation coefficient $(\rho)$ is 0.1667 with a corresponding p-value of 0.017 in the case of the $\mathrm{BC}$ weight matrix and 0.1941 with a p-value of 0.042 when using the ED weight matrix. That is, spatial dependence of job opportunities can be detected and confirmed at the $5 \%$ level in both cases, implying that job opportunities provided in a PCC can affect and be affected by neighbors' job opportunities. Third, in the case of the BC weight matrix, it is observed that $\ln E S$ and $H S R$ are significant at the 5\% level with respective coefficients of 0.4034 and 0.0914 , while $\ln C S$ is insignificant. Similar findings can be obtained in the case of the ED weight matrix. That is, at the 5\% level, significant $\ln E S$ and $H S R$ are found, while insignificant $\ln C S$ is observed. This reveals that, at the national level, economy size and the opening of the HSR can contribute to local job opportunities, while the contribution of capital stock is insignificant.

\section{Insert Table 3 about here}

As addressed above, however, the estimated coefficients of $\ln E S$ and $H S R$ do not straightforwardly reflect their marginal effects on job opportunities. For this reason, the average direct, indirect, and total effects of $\ln E S$ and $H S R$ on job opportunities are calculated. As shown in Table 3, $\ln E S$ has significantly positive direct effects (with estimates of 0.4108 and 0.3916), indirect effects (with estimates of 0.0759 and 0.0879), and total effects (with estimates of 0.4868 and 0.4795 ) on job opportunities in both cases. Turning to $H S R$, it has significantly positive direct effects (magnitudes are 0.0953 and 0.0960 ) and total effects (magnitudes are 0.1124 and 0.1202 ) but insignificant indirect effects in both cases. In this regard, the estimated coefficients of $\ln E S$ and $H S R$ underestimate the marginal effects, represented by the direct effects, on job opportunities due to its exclusion of the positive spillover feedback effects. Meanwhile, spatial spillovers, represented by the indirect effect, of $\ln E S$ and $H S R$ can be measured separately.

\subsection{Spatial spillovers at the regional level}

As discussed above, regional disparities of job opportunities in China has challenged the 
harmonious development objective and become a major concern for the central government (Fan et al., 2011). In response to this concern, a cross-regional analysis ${ }^{6}$, including the eastern/northeastern, central, and western regions (Figure 1), is carried out to examine how job opportunities distribute across regions, shedding some light on the harmonious development. For each region, the most appropriate specification of the SPDM is estimated and reported in Tables 4, 5 , and 6 , respectively.

\section{Insert Figure 1 about here \\ Insert Table 4 about here \\ Insert Table 5 about here \\ Insert Table 6 about here}

In the eastern/northeastern region, the SDM with the $\mathrm{BC}$ weight matrix outperforms other specifications, but there is no evidence to support the use of the ED weight matrix. First, as reported in Table 4, the Hausman test is significant at the $10 \%$ level, indicating that the spatial fixed effect model can be selected to capture the individual effect. Second, at the $1 \%$ level, a significant $\rho$ is observed with the coefficient of 0.1792 , confirming significant spatial dependence of job opportunities in this region. Third, turning to explanatory variables, $\ln E S$, $w \times \ln C S$ and $w \times H S R$ are significant at the $1 \%$ level, with coefficients of $0.6913,-0.2028$, and 0.1866 , respectively. This implies that job opportunities in a PCC in this region are mainly driven by the local economy size while the contributions of the local capital stock and the HSR service are insignificant. In particular, local job opportunities can be negatively affected by neighbors' capital stocks but positively affected by neighboring HSR services. Finally, focusing mainly on the indirect effects, there are significant positive spillovers for $\ln E S$ and $H S R$, with estimates of 0.1299 and 0.1925 , respectively, but significant negative spillovers for $\ln C S$ with an estimate of -0.2088 . That is, for a PCC in this region, local job opportunities are increased by neighboring economy sizes and HSR services but are decreased by neighboring capital stocks.

In the central region, shown in Table 5, the SDM is empirically supported. Based on the

\footnotetext{
${ }^{6}$ Eastern/northeastern: Beijing, Tianjin, Hebei, Shanghai, Jiangsu, Zhejiang, Fujian, Shandong, Guangdong, Hainan, Liaoning, Jilin, Heilongjiang; Central: Shanxi, Henan, Anhui, Jiangxi, Hubei, Hunan; Western: Inner Mongolia, Guangxi, Chongqing, Sichuan, Guizhou, Yunnan, Tibet, Shaanxi, Gansu, Qinghai, Ningxia, Xinjiang (http://www.stats.gov.cn/ztjc/zthd/sjtjr/dejtjkfr/tjkp/201106/t20110613_71947.htm).
} 
Hausman test, the spatial fixed effect model is suggested to describe individual effects regardless of weight matrix. The significant $\rho$ is obtained with estimates of 0.3179 for the $\mathrm{BC}$ weight matrix and 0.2772 for the ED weight matrix, implying that a PCC's job opportunities can be affected by neighbors' job opportunities. It is also the case that local job opportunities can be increased by the local economy size and capital stock but be decreased by neighbors' capital stocks regardless of the spatial weight matrix. In addition, the indirect effects show that there are significant positive spatial spillovers for $\ln E S$, with the estimates of 0.1674 when using the $\mathrm{BC}$ weight matrix and 0.1226 when using the ED weight matrix. However, significant negative spatial spillovers are found for $\ln C S$, with estimates of -0.3910 and -0.4030 depending on the selection of the spatial weight matrix.

With respect to the western region, reported in Table 6, the SEM with the $\mathrm{BC}$ weight matrix and the SAR with the ED weight matrix are identified as appropriate models. As suggested by the Hausman test, the fixed effect model is used. When using the $\mathrm{BC}$ weight matrix, it is found that $\ln C S$ has a significant positive contribution to job opportunities while the contributions of $\ln E S$ and HSR are insignificant. The significant $\lambda$ with the estimate of -0.1214 means that negative spatial influence comes through the error terms in this region. Similar results can be obtained when using the ED weight matrix. That is, significant $\ln C S$, with the estimate of 0.1547, but insignificant $\ln E S$ and $H S R$ are found. The significant spatial autocorrelation is detected and confirmed by the significant $\rho$ with the estimate of 0.2847 . The indirect effect shows evidence of significant positive spatial spillovers for $\ln C S$ with the estimate of 0.0585 .

\section{Discussions and policy implications}

First, empirical results provide evidence for the use of static spatial panel data models to examine how job opportunities interact among PCCs (Arbués et al., 2015). That is, the number of job opportunities in the previous year has no significant contribution to the current year's job opportunities. Interestingly, the presence of significant spatial dependence implies that the current year's job opportunities in a PCC can be affected by its neighbors' job opportunities in the same year. As a result, a local government should focus not only on its own job opportunities but pay some attention to its neighbors' job opportunities when using different policy tools to promote employment. In the meantime, cross-regional collaboration is highly encouraged to promote 
equilibrium employment in a wider region.

Second, job opportunities are mainly driven by the local economy size in all regions except the western region, while the contribution of the local capital stock is significant only in the central and western regions, requiring governments at different levels to revisit the role of capital stock in promoting employment. Specifically, job opportunities in the central and western regions can be increased by expanding capital investments, which does not hold in the eastern/northeastern region. This can be partly explained by the diminishing marginal product of capital (Shi et al., 2016). On average, PCCs in the eastern/northeastern region have a higher level of capital stock, producing less output from an additional unit of capital input and then absorbing less labor input. Moreover, the cross-regional analysis shows that an increase in neighboring capital stocks tends to decrease local job opportunities only in the eastern/northeastern and central regions. Thus, the central government can use capital investment as a tool to balance the distribution of job opportunities among different PCCs to achieve the harmonious development objective.

Third, regarding the opening of the HSR, it can promote job opportunities at the national level, but not necessarily in each region. There is evidence to indicate that the opening of the HSR in neighboring cities can create more job opportunities only in the eastern/northeastern region. Moreover, by putting the emphasis on spatial spillovers, it can be clearly seen that the indirect effect accounts for nearly $94 \%$ of the total effect that the opening of the HSR on the number of job opportunities in this region. In this sense, the HSR investments can be a driving force for nationwide job creation. However, more importantly, the central government needs to consider regional disparities when investing in the HSR to promote job opportunities. This finding also emphasizes the coordinative role of the central government in planning the future HSR networks and allocating transportation resources across regions.

\section{Conclusion}

The creation and distribution of job opportunities have traditionally been the primary concern for the local and central governments, which is examined in this study. In view of this, we start by introducing the C-D production function framework to single out the most important factors affecting the number of job opportunities, avoiding an overly detailed investigation of influences 
on labor demand and supply. Then, the use of a general SPDM without extra restrictions on the model specification allows us to investigate spatial dependence of job opportunities among 30 Chinese PCCs from 2002 to 2016, giving special attention to spatial spillovers of the opening of the HSR. Our findings can be summarized here.

First, after examining different forms of the SPDM, the most appropriate spatial panel data model can be identified. It is widely believed that there could be great regional disparities in terms of job opportunities in China due to different geographic, cultural and economic conditions, requiring different model specifications. At the national level, the SAR is appropriate to capture spatial dependence of job opportunities. At the regional level, there is evidence to support the use of the SDM in the eastern/northeastern and the central regions, while the SEM and the SAR are identified as suitable models in the western region depending on the use of the spatial weight matrix. Second, significant spatial dependence of job opportunities is detected and confirmed in each region, implying that job opportunities provided in a PCC can affect and be affected by neighbors' job opportunities. Third, the empirical results show that the local economy size makes significant positive contribution to job opportunities in all regions except for the western region, while the contribution of capital stock is significant only in the central and western regions. As a relatively new transportation mode, the HSR can contribute to job opportunities at the national level, but there is no evidence to support its contribution in each region. Finally, the indirect effects show that significant spatial spillovers exist for economy size in all region except for the western region, for capital size in all regions, and for the HSR only in the eastern/northeastern region.

This study has major implications for government decisions. Firstly, the findings can deepen the understanding of how local job opportunities can affect and be affected by neighbors, encouraging cross-regional collaboration to promote employment. Secondly, this study can assist the central government in better planning future HSR networks and allocating transportation resources by adequately incorporating spatial spillovers of the opening of the HSR among different regions. In addition, with the development of China's Belt and Road Initiative (BRI), the Chinese government has made great efforts to promote the HSR projects in the BRI countries, which aims to improve regional connectivity and accessibility (Liu and Lim, 2019). Due to diverse economies and cultures among different BRI countries, the cross-regional analysis of China's 
HSR experience can be a useful example to help them to develop the HSR networks.

Despite these implications, this study can be extended in at least two directions. One natural extension is to investigate the industry-level distribution of job opportunities as influenced by the opening of the HSR. The other extension is to use the real data on HSR investments, allowing us to split the HSR investments from general capital investments and provide more quantitative evidence of the specific impacts of HSR.

\section{Acknowledgement}

This study is supported in part by the Korea Foundation and Zhejiang University Education Foundation Global Partnership Fund.

\section{References}

Anselin, L., Griffith, D. A., 1988. Do spatial effects really matter in regression analysis? Papers in Regional Science, 65 (1), 11-34.

Arbués, P., Baños, J. F., Mayor, M., 2015. The spatial productivity of transportation infrastructure. Transportation Research Part A, 75, 166-177.

Arrow, K. J., Chenery, H. B., Minhas, B. S., Solow, R. M., 1961. Capital-labor substitution and economic efficiency. The review of Economics and Statistics, 43 (3), 225-250.

Autor, D. H., Dorn, D., Hanson, G. H., 2015. Untangling trade and technology: Evidence from local labour market. The Economic Journal, 125 (584), 621-646.

Beladi, H., Chaudhuri, S., Yabuuchi, S., 2008. Can International factor mobility reduce wage inequality in a dual economy? Review of International Economics, 16 (5), 893-903.

Bellemare, M. F., Masaki, T., Pepinsky, T. B., 2017. Lagged explanatory variables and the estimation of causal effect. The Journal of Politics, 79 (3), 949-963.

Burgessm S., Profit, S., 2001. Externalities in the matching of workers and firms in Britain. Labour Economics, 8 (3-4), 313-333.

Chen, C. L., Hall, P., 2012. The wider spatial-economic impacts of high-speed trains: a comparative case study of Manchester and Lille sub-regions. Journal of Transport Geography, 24, 89-110.

Chen, Z., Xue, J., Rose, A. Z., Haynes, K. E., 2016. The impact of high-speed rail investment on economic and environmental change in China: A dynamic CGE analysis. Transportation Research Part A, 92, 232-245. Chen, Z., Haynes, K. E., 2017. Impact of high-speed rail on regional economic disparity in China. Journal of Transport Geography, 65, 80-91.

Coto-Millán, P., Inglada, V., Rey, B., 2007. Effects of network economies in high-speed rail: the Spanish case. The Annals of Regional Science, 41 (4), 911-925.

Dalenberg, D. R., Partridge, M. D., Rickman, D. S., 1998. Public infrastructure: port or jobs creator? Public Finance Review, 26 (1), 24+.

Decressin, J., Fatás, A., 1995. Regional labor market dynamics in Europe. European Economic Review, 39 (9), 1627-1655. 
Deng, M., 2014. The relation between transport infrastructure and employment density in Chinese cities: Endogenous relation and spatial spillovers (In Chinese). Economic Management, 36 (1), 163-174.

Dong, X., 2018. High-speed railway and urban sectoral employment in China. Transportation Research Part A: Policy and Practice, 116, 603-621.

Dustmann, C., Schönberg, U., Stuhler, J., 2017. Labor supply shocks, native wages, and the adjustment of local employment. The Quarterly Journal of Economics, 132 (1), 435-483.

Eliasson, K., Lindgren, U., Westerlund, O., 2003. Geographical labour mobility: Migration or commuting? Regional Studies, 37 (8), 827-837.

Fan, S., Kanbur, R., Zhang, X., 2011. China's regional disparities: Experience and policy. Review of Development Finance, 1, 47-56.

Finnie, R., 2004. Who moves? A logit model analysis of inter-provincial migration in Canada. Applied Economics, 36 (16), 1759-1779.

Garmendia, M., de Ureña, J. M., Ribalaygua, C., Leal, J., Coronado, J. M., 2008. Urban residential development in isolated small cities that are partially integrated in metropolitan areas by high speed train. European Urban and Regional Studies, 15 (3), 249-264.

Goldsmith, S. B., 1951. A Perpetual Inventory of National Wealth. Studies in Income and Wealth, 14, New York: NBER.

Golgher, A. B., Voss, P. R., 2016. How to interpret the coefficients of spatial models: Spillovers, direct and indirect effects. Spatial Demography, 4 (3), 175-205.

Guirao, B., Lara-Galera, A., Campa, J. L., 2017. High speed rail commuting impacts on labour migration: The case of the concentration of metropolis in the Madrid functional area. Land Use Policy, 66, 131-140.

Haas, A., Osland, L., 2014. Commuting, migration, housing and labour markets: Complex interactions. Urban Studies, 51 (3), 463-476.

Haller, P., Heuermann, D. F., 2016. Job search and hiring in local labor markets: Spillovers in regional matching functions. Regional Science and Urban Economics, 60, 125-138.

Hatch, N. W., Dyer, J. H., 2004. Human capital and learning as a source of sustainable competitive advantage. Strategic Management Journal, 25, 1155-1178.

Hensher, D. A., Ellison, R. B., Mulley, C., 2014. Assessing the employment agglomeration and social accessibility impacts of high speed rail in Eastern Australia. Transportation, 41 (3), 463-493.

Heuermann, D. F., Schmieder, J. F., 2019. The effect of infrastructure on worker mobility: evidence from high-speed rail expansion in Germany. Journal of Economic Geography, 19 (2), 335-372.

Higashi, Y., 2018. Spatial spillovers in job matching: Evidence from the Japanese local labor markets. Journal of The Japanese and International Economies, 50, 1-15.

$\mathrm{Hu}$, A., Liu, S., 2009. Transportation, economic growth and spillovers: conclusion based on spatial econometrics. China Industrial Economics, 5, 5-14.

Hynninen, S. M., 2005. Matching across space: Evidence from Finland. Labour, 19 (4), 749-765.

Ilmakunnas, P., Pesola, H., 2003. Regional labour market matching functions and efficiency analysis. Labour, 17 (3), 413-437.

Kawabata, M., Abe, Y., 2018. Intra-metropolitan spatial patterns of female labor force participation and commute times in Tokyo. Regional Science and Urban Economics, 68, 291-303.

Kim, K. S., 2000. High-speed rail developments and spatial restructuring: A case study of the Capital region in South Korea. Cities, 17 (4), 251-262.

Kondo, K., 2015. Spatial persistence of Japanese unemployment rates. Japan and the World Economy, 36, 113-122. 
Lee, D., Wolpin, K. I., 2006. Intersectoral labor mobility and the growth of the service sector. Econometrica, $74(1), 1-46$.

Lee, S. K., Kim, E., 2015. The effects of highway investments on production costs in the Korean manufacturing sector. International Journal of Urban Sciences, 19 (2), 182-191.

LeSage, J., Pace, R. K., 2009. Introduction to spatial Econometrics. New York: Chapman and Hall/CRC.

Levinson, D. M., 2012. Accessibility impacts of high-speed rail. Journal of Transport Geography, 22, 288-291.

Li, K. X., Jin, M., Qi, G., Shi, W., Ng, A. K., 2018. Logistics as a driving force for development under the belt and road initiative-the Chinese model for developing countries. Transport Reviews, 38 (4), 457-478.

Liu, H., Lim, G., 2019. The political economy of a rising China in Southeast Asia: Malaysia's response to the Belt and Road Initiative. Journal of Contemporary China, 28 (116), 216-231.

Lottmann, F., 2012. Spatial dependencies in German matching functions. Regional Science and Urban Economics, 42 (1-2), 27-41.

Mankiw, N. G., 2010. Macroeconomics, $7^{\text {th }}$ edition, Worth Publishers, New York, USA.

Mankiw, N. G., 2015. Principles of microeconomics, 7the edition, Cengage Learning, USA.

Manning, A., Petrongolo, B., 2017. How local are labor markets? Evidence from a spatial job search model. American Economic Review, 107 (10), 2877-2907.

McLaughlin, K., Bils, M., 2001. Interindustry mobility and the cyclical upgrading of labor. Journal of Labor Economics, 19 (1), 94-135.

Meng, X., Lin, S., Zhu, X., 2018. The resource redistribution effect of high-speed rail stations on the economic growth of neighboring regions: Evidence from China. Transport Policy, 68, 178-191.

Mitra, D., Ranjan, P., 2010. Offshoring and unemployment: The role of search frictions labor mobility. Journal of International Economics, 81 (2), 219-229.

Moran, P. A. P., 1950. Notes on continuous stochastic phenomena. Biometrika, 37 (1-2), 17-23.

Niebuhr, A., 2003. Spatial interaction and regional unemployment in Europe. European Journal of Spatial Development, https://pdfs.semanticscholar.org/d13b/67eccdee214221762e109fc7ed5a30670c7f.pdf

Próchniak, M., Witkowski, B., 2014. Alternative weighting schemes in spatial analysis of GDP per capita convergence. Quantitative Methods in Economics, XV (2), 198-208.

Renkow, M., 2003. Employment growth, worker mobility, and rural economic development. American Journal of Agricultural Economics, 85 (2), 503-513.

Rhee, K. A., Kim, J. K., Lee, Y. I., Ulfarsson, G. F., 2016. Spatial regression analysis of traffic crashes in Seoul. Accident Analysis and Prevention, 91, 190-199.

Sasaki, K., Ohashi, T., Ando, A., 1997. High-speed rail transit impact on regional systems: Does the Shinkansen contribute to dispersion? Annals of Regional Science, 31 (1), 77-98.

Seeborg, M. C., Jin, Z., Zhu, Y., 2000. The new rural-urban labor mobility in China: Causes and implications. Journal of Socio-Economics, 29 (1), 39-56.

Shan, H. (2008). Reestimating the capital stock of China: 1952-2006. The Journal of Quantitative \&Technical Economics, 10, 17-31.

Shi, W., Bang, H. S., Li, X. K., 2016. A cross-region analysis of the output elasticity of transport investment in China. Maritime Policy \& Management, 43 (2), 222-241.

Simonen, J., Svento, R., McCann, P., 2016. The regional and sectoral mobility of high-tech workers: insights from Finland. The Annals of Regional Science, 56 (2), 341-368.

Yu, N., Jong, M. de, Storm, S., Mi, J., 2013. Spatial spillover effects of transport infrastructure: evidence from Chinese regions. Journal of Transport Geography, 28, 56-66. 


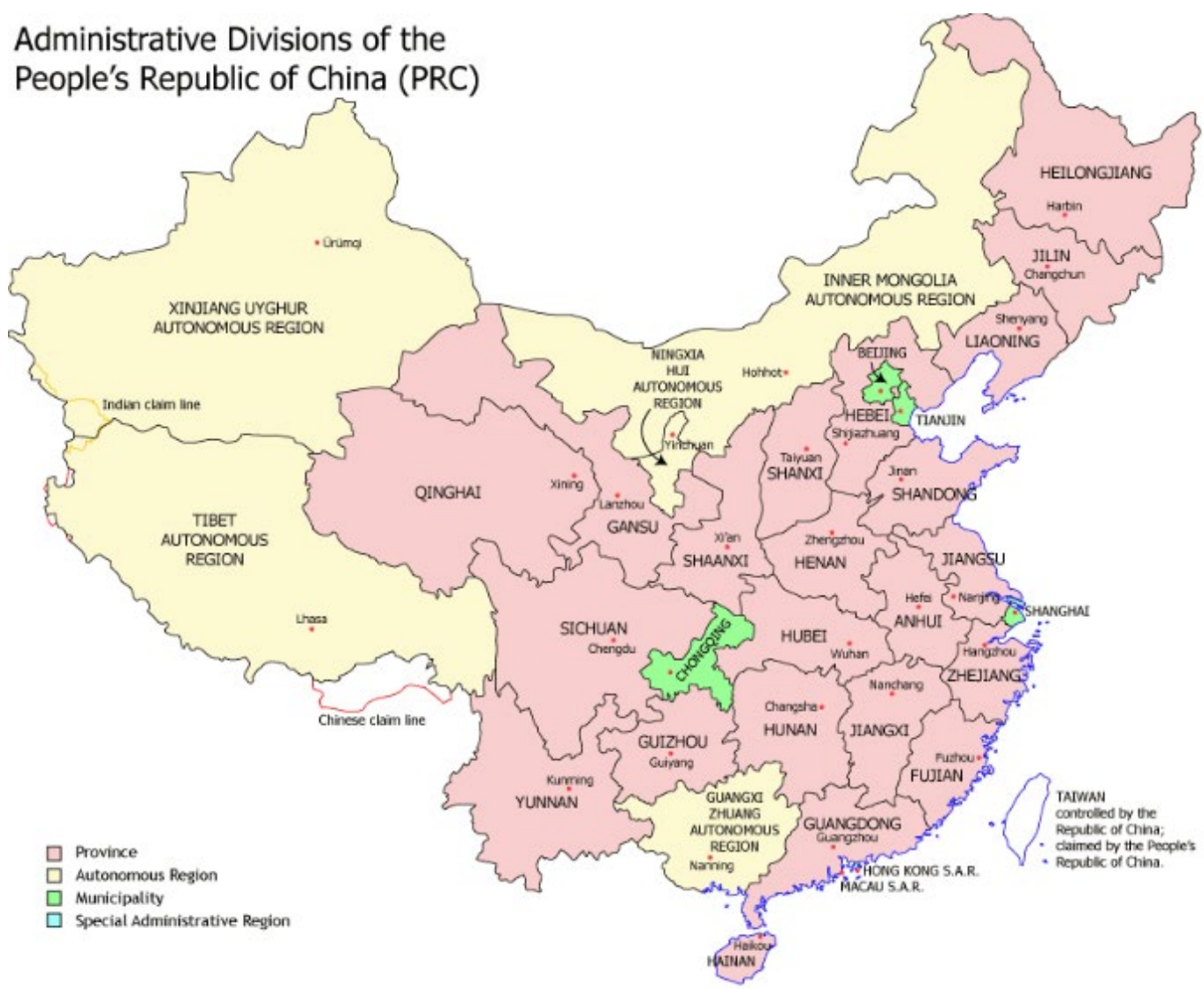

Figure 1 Provinces and provincial capital cities in China

Source: https://commons.wikimedia.org/wiki/File:China administrative.gif 
Table 1 Summary statistics of variables

\begin{tabular}{llllll}
\hline Variable & Mean & Median & Standard Deviation & Minimum & Maximum \\
\hline Job opportunities (JO) & 270.47 & 178.81 & 271.83 & 37.4492 & 1729.08 \\
Economy size (ES) & 28399116.54 & 18713547.45 & 28337160.55 & 1205703.62 & 164558157.4 \\
Capital stock (CS) & 79695117.82 & 48943630.87 & 83682618.82 & 1942797.45 & 514244185.8 \\
\hline
\end{tabular}

Notes: JO is measured in 10,000 persons; ES and CS are measured in 100 million yuan (Chinese

RMB).

Table 2 Test for spatial autocorrelation Moran's $I$

\begin{tabular}{llllll}
\hline Year & Moran's $I$ & p-value & Year & Moran's $I$ & p-value \\
\hline 2002 & $0.164 * * *$ & 0.007 & 2010 & $0.263 * * *$ & 0.000 \\
2003 & $0.182^{* * *}$ & 0.003 & 2011 & $0.305 * * *$ & 0.000 \\
2004 & $0.151 * * *$ & 0.003 & 2012 & $0.275^{* * *}$ & 0.000 \\
2005 & $0.167 * * *$ & 0.003 & 2013 & $0.247 * * *$ & 0.000 \\
2006 & $0.246 * * *$ & 0.000 & 2014 & $0.172 * * *$ & 0.006 \\
2007 & $0.250 * * *$ & 0.000 & 2015 & $0.226 * * *$ & 0.001 \\
2008 & $0.253 * * *$ & 0.000 & 2016 & $0.306 * * *$ & 0.000 \\
2009 & $0.255^{* * *}$ & 0.000 & & & \\
\hline
\end{tabular}

Note: $* * *$ statistical significance at the $1 \%$ level. 
Table 3 Estimation results of the SAR at the national level

\begin{tabular}{|c|c|c|c|c|c|c|c|c|}
\hline Variable & BC weight & Direct effect & Indirect effect & Total effect & ED weight & Direct effect & Indirect effect & Total effect \\
\hline $\ln E S$ & $0.4034 * * *$ & $0.4108 * * *$ & $0.0759 *$ & $0.4868 * * *$ & $0.3843 * * *$ & $0.3916^{* * *}$ & $0.0879 *$ & $0.4795 * * *$ \\
\hline & $(0.001)$ & $(0.001)$ & $(0.067)$ & $(0.001)$ & $(0.005)$ & $(0.005)$ & $(0.089)$ & $(0.003)$ \\
\hline $\ln C S$ & 0.01297 & 0.0099 & 0.0014 & 0.0114 & 0.0140 & 0.0184 & 0.0037 & 0.0145 \\
\hline & $(0.831)$ & $(0.874)$ & $(0.907)$ & $(0.878)$ & $(0.826)$ & $(0.869)$ & $(0.840)$ & $(0.860)$ \\
\hline$H S R$ & $0.0914 * *$ & $0.0953 * *$ & 0.0171 & $0.1124 * *$ & $0.0921 * *$ & $0.0960 * * *$ & 0.0242 & $0.1202 * *$ \\
\hline$\rho$ & $\begin{array}{l}(0.023) \\
0.1667 * *\end{array}$ & $(0.016)$ & $(0.104)$ & $(0.014)$ & $\begin{array}{l}(0.013) \\
0.1941 * *\end{array}$ & $(0.008)$ & $(0.202)$ & $(0.015)$ \\
\hline & $(0.017)$ & & & & $(0.042)$ & & & \\
\hline $\mathrm{R}^{2}$ & 0.6532 & & & & 0.8031 & & & \\
\hline Log-pseudolikelihood & 235.0539 & & & & 235.0539 & & & \\
\hline Hausman test & $\begin{array}{l}14.85 * * * \\
(0.005)\end{array}$ & & & & $\begin{array}{l}12.97 * * \\
(0.0114)\end{array}$ & & & \\
\hline
\end{tabular}

Note: p-values are in parentheses. *Statistical significance at the $10 \%$ level. $* *$ Statistical significance at the $5 \%$ level. $* * *$ Statistical significance at the $1 \%$ level. 
Table 4 Estimation results of SDM for eastern/northeastern cities (BC weight matrix)

\begin{tabular}{|c|c|c|c|c|}
\hline Variable & Coefficient & Direct effect & Indirect effect & Total effect \\
\hline $\ln E S$ & $0.6913 * * *$ & $0.7092 * * *$ & $0.1299 * *$ & $0.8392 * * *$ \\
\hline & $(0.000)$ & $(0.000)$ & $(0.030)$ & $(0.000)$ \\
\hline $\ln C S$ & 0.0201 & -0.0004 & $-0.2088 * * *$ & $-0.2092 *$ \\
\hline$H S R$ & $\begin{array}{l}(0.807) \\
-0.0060\end{array}$ & $\begin{array}{l}(0.996) \\
0.0129\end{array}$ & $\begin{array}{l}(0.002) \\
0.1925^{* * *}\end{array}$ & $\begin{array}{l}(0.090) \\
0.2054 * * *\end{array}$ \\
\hline & $(0.899)$ & $(0.767)$ & $(0.000)$ & $(0.000)$ \\
\hline$w \times \ln C S$ & $\begin{array}{l}-0.2028^{* * *} \\
(0.001)\end{array}$ & & & \\
\hline$w \times H S R$ & $\begin{array}{l}0.1866^{* * * *} \\
(0.000)\end{array}$ & & & \\
\hline$\rho$ & $\begin{array}{l}0.1792 * * * \\
(0.004)\end{array}$ & & & \\
\hline $\mathrm{R}^{2}$ & 0.5908 & & & \\
\hline Log-pseudolikelihood & 98.5004 & & & \\
\hline Hausman test & $\begin{array}{l}11.22 * \\
(0.0818) \\
\end{array}$ & & & \\
\hline
\end{tabular}

Note: p-values are in parentheses. *Statistical significance at the $10 \%$ level. **Statistical significance at the $5 \%$ level. ***Statistical significance at the $1 \%$ level. 
Table 5 Estimation results of SDM for central cities

\begin{tabular}{|c|c|c|c|c|c|c|c|c|}
\hline Variable & BC weight & Direct effect & Indirect effect & Total effect & ED weight & Direct effect & Indirect effect & Total effect \\
\hline $\ln E S$ & $0.3902 * *$ & $0.4146^{* *}$ & $0.1674^{*}$ & $0.5821 * *$ & $0.3443 * *$ & $0.3609 * *$ & $0.1226^{*}$ & $0.4835 * *$ \\
\hline & $(0.018)$ & $(0.017)$ & $(0.067)$ & $(0.014)$ & $(0.026)$ & $(0.025)$ & $(0.065)$ & $(0.020)$ \\
\hline $\ln C S$ & $0.3656^{* * *}$ & $0.3194 * * *$ & $-0.3910 * * *$ & -0.0716 & $0.4405 * * *$ & $0.4025 * * *$ & $-0.4030 * * *$ & -0.0006 \\
\hline$H S R$ & $\begin{array}{l}(0.000) \\
0.0854\end{array}$ & $\begin{array}{l}(0.000) \\
0.0957 *\end{array}$ & $\begin{array}{l}(0.000) \\
0.0455\end{array}$ & $\begin{array}{l}(0.544) \\
0.1413\end{array}$ & $\begin{array}{l}(0.000) \\
0.0883\end{array}$ & $\begin{array}{l}(0.000) \\
0.0969\end{array}$ & $\begin{array}{l}(0.000) \\
0.0384\end{array}$ & $\begin{array}{l}(0.995) \\
0.1353\end{array}$ \\
\hline$w \times \ln C S$ & $\begin{array}{l}(0.120) \\
-0.4045 * * *\end{array}$ & $(0.097)$ & $(0.259)$ & $(0.133)$ & $\begin{array}{l}(0.129) \\
-0.4347 * * *\end{array}$ & $(0.104)$ & $(0.242)$ & $(0.130)$ \\
\hline$\rho$ & $\begin{array}{l}(0.000) \\
0.3179 * * *\end{array}$ & & & & $\begin{array}{l}(0.000) \\
0.2772 * * *\end{array}$ & & & \\
\hline & $(0.003)$ & & & & $(0.002)$ & & & \\
\hline $\mathrm{R}^{2}$ & 0.8556 & & & & 0.8539 & & & \\
\hline Log-pseudolikelihood & 72.8715 & & & & 72.8715 & & & \\
\hline Hausman test & $\begin{array}{l}68.27 * * * \\
(0.000)\end{array}$ & & & & $\begin{array}{l}223.30 * * * \\
(0.000)\end{array}$ & & & \\
\hline
\end{tabular}

Note: p-values are in parentheses. ${ }^{*}$ Statistical significance at the $10 \%$ level. $* *$ Statistical significance at the $5 \%$ level. $* * *$ Statistical significance at the $1 \%$ level. 
Table 6 Estimation results of SPDM for western cities

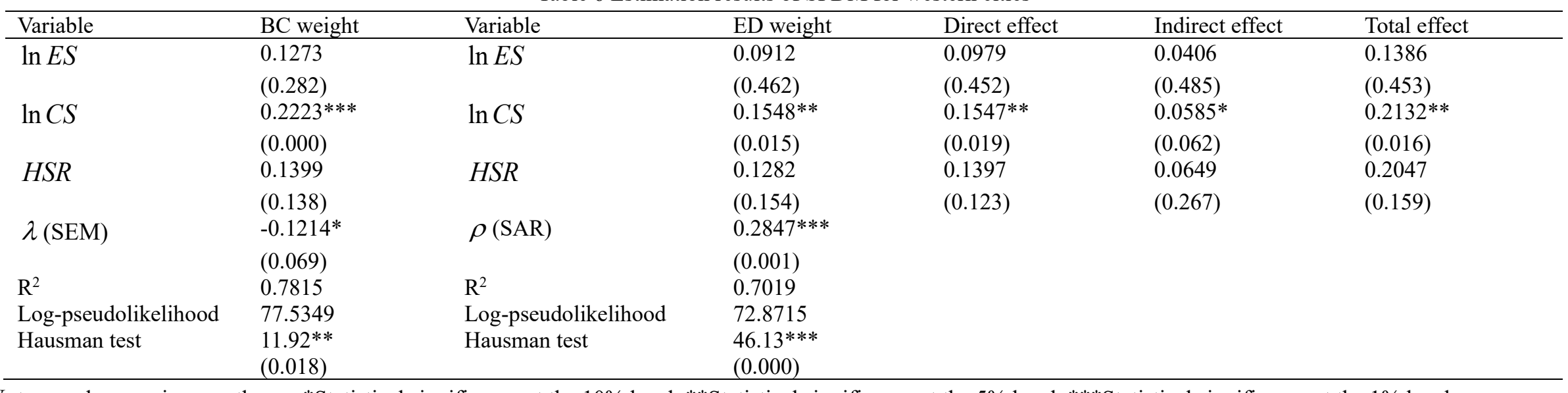

Note: p-values are in parentheses. ${ }^{*}$ Statistical significance at the $10 \%$ level. $* *$ Statistical significance at the $5 \%$ level. $* * *$ Statistical significance at the $1 \%$ level. 